https://doi.org/10.18485/dpls_pld.2020.6.ch12

$811.131 .1{ }^{\prime 2} 243$

$811.131 .1^{\prime} 42$

Nevena P. Ceković

Univerzitet u Beogradu

\title{
METATEKSTUALNA KOMPETENCIJA UČENIKA NA SREDNJEM NIVOU ZNANJA ITALIJANSKOG KAO DRUGOG JEZIKA
}

\begin{abstract}
Sažetak: Istražili smo metatekstualne diskursne markere, bitan faktor diskursne kompetencije i pragmatičke fluentnosti u J2, polazeći od longitudinalnog korpusa sačinjenog od audio snimaka i ortografskih transkripata 100 minuta asimetričnih interakcija u kojima je, u razmaku od 12 meseci, učestvovalo 10 srbofonih studenata italijanistike na srednjem nivou znanja. Kvalitativno-kvantitativnom analizom su otkrivene i ekscerptima iz korpusa ilustrovane demarkacija, fokalizacija i reformulacija (parafraza, korekcija, egzemplifikacija), uz izdvajanje najučestalijih formi i funkcija. Rezultati su pokazali da porast kompetencije dovodi do proširenja obima formi i funkcija metatekstualnih markera, kao i do uvećanja udela metatekstualnih funkcija u sveukupnom obimu funkcija diskursnih markera zabeleženih u korpusu.
\end{abstract}

Ključne reči: italijanski J2, metatekstualni diskursni markeri, pragmatička kompetencija, srbofoni studenti, korpus.

\section{Uvod}

Poslednjih decenija diskursni markeri (DM), kao jedan od elemenata metatekstualne kompetencije učenika, predstavljaju predmet sve intenzivnijih proučavanja na polju primenjene lingvistike (Bardel 2003, Ferraris 2004, Andorno 2007, Guil et al. 2008, Hernández 2008, Jones 2011, Nigoević \& Sučić 2011, Jafrancesco 2015, Ceković 2014, 2016, 2018a/b). Naročito je u porastu broj istraživanja o usvajanju DM u drugom (J2) ili stranom (Js) jeziku baziranih na korpusima (cfr. npr. Bardel 2003, Andorno 2007, Fung \& Carter 2007, Romero Trillo 2002, Carlsen 2010), čime se pruža egzaktnija potpora dobijenim rezultatima i omogućava njihova upo- 
redivost. Istraživači okupljeni oko projekata iz kojih nastaju takvi korpusi sve više pažnje poklanjanju proučavanju markera, između ostalog i u italijanskom kao J2, i to kod imigranata koji žive u Italiji (projekat Univerziteta u Paviji, tzv. Progetto di Pavia, Andorno 2007, 2008; Rastelli 2003) ili kod učenika u kontekstu Js, u Švedskoj (Univerziteti u Stokholmu i Lundu, Bardel 2003, Wiberg 2004, 2003), Španiji (grupa A.Ma.Dis sa Univerziteta u Madridu, okupljena oko projekata Adquisición de marcadores del discurso en la interacción de apprendices de italiano L2 i Marcadores discursivos y construcción interaccional del diálogo en italiano L2, Bini \& Pernas 2007, Guil et al. 2008, Guil 2009a/b, Borreguero Zuloaga 2009, Borreguero \& Pernas 2010, Bazzanella \& Borreguero Zuloaga 2011, Pernas, Gillani \& Cacchione 2011), a od nedavno i u Srbiji (Univerzitet u Beogradu, Ceković 2014, 2016, Ceković \& Radojević 2015).

Premda se ovakvim studijama ostvaruje sve bolji uvid u osnovne odlike ovih polifunkcionalnih konverzacionih partikula, sekvencijalnost njihovog usvajanja u J2 i značaj za učenikovu pragmatičko-diskursnu kompetenciju, ipak je i dalje nedovoljan broj longitudinalnih i kvantitativnih studija koji bi takve nalaze potkrepile dodatnim rezultatima. Sem toga, sve je rašireniji i stav kojim se skreće pažnja na neophodnost uvođenja jednog sistematskog pristupa markerima u didaktičkom procesu (Fung \& Carter 2007, Müller 2005, Ceković 2016, 2018b).

U tom smislu, ovaj rad teži da pruži bolji pogled na DM i njihovu upotrebu u okvirima metatekstualne kompetencije učenika, s fokusom na srednji nivo znanja italijanskog kao J2. Rad je proistekao iz naše doktorske teze (Ceković 2016) u kojoj se preispituje efikasnost inputa s DM na govornu produkciju studenata Katedre za italijanski jezik i književnost na Filološkom fakultetu Univerziteta u Beogradu. Upravo ovaj kontekst usvajanja italijanskog kao Js poslužio nam je kao osnova da u ovom radu istražimo forme i funkcije metatekstualnih diskursnih markera (MDM): radi se o rečima i izrazima poput diciamo ('recimo'), allora ('dakle'), quindi ('onda'), cioè ('odnosno'), per esempio ('na primer') (cfr. Ceković \& Radojević 2016, Ceković \& Janićijević 2017), koji služe strukturiranju diskursa i koji, posmatrano iz pragmatičke perspektive zajedno sa onim interakcionim, predstavljaju značajan faktor učenikove diskursne kompetencije i pragmatičke fluentnosti u J2 (House 2013, Council of Europe 2001, Diadori et al. 2009). Za potrebe rada pozivamo se na Bazzanellin $(1994,1995)$ pragmatički pristup u okviru kojeg se među metatekstualnim funkcijama markera razlikuju: demarkacija, fokaliza- 
cija i reformulacija, a u okviru ove poslednje još i parafraza, korekcija i egzemplifikacija.

Cilj rada je i da se s posebnim fokusom na MDM preispitaju neke od prethodno postavljenih hipoteza, koje se tiču uvećanja obima različitih formi i funkcija DM sa porastom kompetencije (npr. Jafrancesco 2015) i za koje očekujemo da će biti potvrđene i u pogledu MDM, kao i one o prisustvu raznovrsnih formi markera tek od $\mathrm{B} 2^{+}$nivoa kompetencije (Council of Europe 2001) ili o ispoljavanju svih funkcija DM na B nivou (Jafrancesco 2015), a za koje, na osnovu naših dosadašnjih studija (Ceković 2014) i zaključaka o tome kako (ne)ispoljavanje određenih funkcija zavisi od tipa ispitivane interakcije (Ceković 2016), ne očekujemo da će biti potvrđene u vezi sa MDM.

\section{Transverzalni korpus: prethodno istraživanje}

Analizirajući našu prethodnu studiju (Ceković 2014), u kojoj smo se poslužili transverzalnim korpusom sačinjenim od 90 minuta usmene produkcije stratifikovanog slučajnog uzorka od 20 studenata, na nivoima kompetencije u italijanskom kao Js od A2 do C1 (Council of Europe 2001), definisanim u vidu nastavnih ciljeva za svaku godinu, od I do IV, ustanovili smo da se MDM javljaju već u inicijalnim fazama usvajanja, kao i da je njihova učestalost i raznovrsnost upotrebe u porastu počevši od nivoa B1. Sem toga, generalno gledano, studijom smo otkrili da sa umnožavanjem formi dolazi do proširenja obima funkcija DM između B2 i C1 nivoa (takav je slučaj sa markerom diciamo) i konstatovali pragmatičkodiskursni deficit u govornoj produkciji ispitanika, prouzrokovan teškoćom u planiranju i formulisanju diskursa, a odlikuju ga brojne ispunjene pauze $i$ ispunjivači, prisustvo reformulatora, repetitivna upotreba izvesnih formi, transfer iz J1.

Štaviše, u vezi sa frekventnošću upotrebe DM, rezultati navedene studije ukazali su da su na I i II godini uz ispunjene pauze DM malobrojni (čineći zajedno 18\% i 24\% ukupnog broja produkovanih reči), da su na III godini (11\%) sve manje prisutne ovakve pauze a sve učestalije i raznovrsnije forme i funkcije drugih markera, uključujući i one devijantne, te da je na IV godini (14\%) uočljiv porast učestalosti pojavljivanja markera kao rezultat uvećanog broja ispunjenih pauza prouzrokovanih složenijom tematikom zadatka, kao i konsolidovanja raznih formi i funkcija u govoru studenata na ovom nivou znanja. U pogledu najučestalijih funkcija DM, studija je ukazala prvenstveno na prisustvo glasnih pauza, ispunjivača, 
markera turnusa i slaganja/prijema, ali i reformulatora, naročito učestalih i raznovrsnih od III godine, nakon kojih sledi funkcionalno devijantna upotreba egzemplifikatora non (lo) so, od II godine, kao i prisustvo demarkatora koji se javljaju tek na IV godini.

Detaljnom analizom pomenute studije, s fokusom ovaj put na MDM i to naročito na srednjim nivoima znanja (II i III godina) budući da su oni u žiži naših interesovanja, uočavamo sledeću zastupljenost funkcija i formi prema nivoima kompetencije:

- I godina (A2 $\left.{ }^{+}\right)$: egzemplifikacija (per esempio);

- II godina (B1): egzemplifikacija (non (lo) so (cosa dire), per esempio), korekcija (no), reformulacija ( "mislim” iz J1);

- III godina (B2+): egzemplifikacija (non (lo) so, per esempio), parafraza (non (lo) so, cioè, nel senso, come si dice), korekcija (sì, cioè, non), demarkacija ((e) quindi, comunque, insomma);

- IV godina (C1): egzemplifikacija (per esempio, non (lo) so, diciamo), parafraza (non (lo) so, cioè, (e) quindi), korekcija (non (lo) so, sì, cioè, diciamo), demarkacija ((e) quindi, (e) allora, comunque).

\section{Longitudinalni korpus: aktuelno istraživanje}

Imajući na umu ove nalaze, a naročito raznovrsnost u upotrebi formi i funkcija markera na srednjem tj. B nivou, identifikovanog u vidu prekretnice u procesu usvajanju markera, fokusirali smo se u ovom istraživanju i na drugi, longitudinalan korpus. ${ }^{1}$ Ovaj korpus sačinjen je stoga od audio snimaka govorne produkcije grupe od 10 srbofonih studenata isključivo na $\mathrm{B}$ nivou kompetencije, učesnika asimetričnih interakcija u trajanju od 100 minuta. Prilikom snimanja, obavljenih u razmaku od 12 meseci, upotrebljeni su testovi CILS Univerziteta za strance iz Sijene, i to: pretest nivoa B1, na kraju II godine studija i post-test nivoa B2, na kraju III godine. Snimci su naknadno ortografski transkribovani prema normama korpusa maternjih govornika CLIPS Univerziteta u Napulju (Savy 2005, Ceković-Rakonjac 2012). U pitanju je prost slučajan uzorak, sačinjen od informanata ženskog pola, starosti 19-25 godina, koji uče italijanski duže od 2 godine, a pored engleskog vladaju i drugim stranim jezicima (francuski, katalonski, ruski, grčki, španski ili japanski), boravili su u Italiji 10-60 dana, kontakt sa Js ostvaruju putem časova, medija, prijateljstava. ${ }^{2}$

\footnotetext{
${ }^{1}$ Oba su deo šireg korpusa ITALBEG, koji je realizovan na beogradskoj Italijanistici i sastoji se od 25 sati govornih interakcija, potpuno transkribovanih, sa oko 200.000 tokena, uz učešće 170 različitih informanata (Ceković-Rakonjac 2012, 2013).

2 Detaljan opis uzorka sadržan je u Ceković 2016. Zbog predviđenog obima ovog rada nije bilo
} 


\section{Kvalitativna analiza}

Kvalitativnom analizom su identifikovane i odgovarajućim ekscerptima iz longitudinalnog korpusa ilustrovane sledeće metakstualne funkcije markera u govornoj produkciji studenata:

1. Demarkacija odnosno razgraničavanje delova teksta i organizovanje tematske strukture, koju vrše brojni markeri. Na pre-testu zabeleženi su u ovoj funkciji: anche i qualcos'altro, podvučeni u primeru (1), zatim poi, così, dunque, qualcosa così, altre cose, alla fine, kao i nekolicina markera koji istovremeno mogu služiti i drugim, interakcionim funkcijama, poput eccetera, è tutto i non so (ustupanje reči), allora (uzimanje reči), non so (ispunjavanje), diciamo (modulacija). Na post-testu ispoljeni su kod ispitanika: anche, poi, qualcos'altro/*qualcosa altra, solo questo, qualcosa del genere, simile kojem prethodi o, zatim così via, come ho detto prima, alla fine, te markeri koji istovremeno mogu služiti i ustupanju reči: non (lo) so, eccetera, cosi. ${ }^{3}$

(1) C: $<$ ehm $>$ quando ho $<$ oo $>$ tempo $<0 o>$ libero $<$ ehm $>$ amo $<o o>$ passeggiare con i miei amici $<i i>0<0 o><e e h>$ giocare tennis $o<o o>$ pallavolo $\#<E>o<o o>\#$ qualcos'altro

$E: \#<C><m h m h>\#$

$C:<e h m>$ anche amo $<o o><e e h>$ giocare con mio cane, è una cosa interessante $<$ ehm $>$ di se $+/$ di solito amo $<$ ehm $><$ tongueclick $><$ eeh $><e e h>*$ giocarre agli scacchi $\#<E>$ con\# mio fratello $<$ eeh $>$ o con mio pa_dre

$E: \#<C><m h m h>\#<m h m h>$

C: $<$ ehm $>$ a casa $<a a><e e h>$ anche $<e h m>$ amo $<o o><e e h>$ guardare uno film $<m m>o<o o><e h m><e e h><$ tongue-click $>$ $<$ eeh $>$ leggere libro $<$ inspiration $>$

$E:<m h m h>$

C: e per il *memento sto leggendo un libro su $<$ eeh $>$ su Africa, $\#<E>$ ë\# un libro molto interessante e anche $<e h m>$ amo $<e e h>$ leggere $i$ gialli

$E: \#<C><m h m h>\#<m h m h>(\mathrm{B} 1, \mathrm{~S} 9)^{4}$

moguće sprovesti individualno praćenje ispitanika; stoga smo se ograničili na analizu (kvantitativnih i većine kvalitativnih) podataka na grupnoj osnovi.

${ }^{3}$ Za ortografsku transkripciju upotrebljeni su u primerima sledeći simboli: $C$ kandidat, $E$ ispitivač, $<>$ komentari transkriptora (ispunjene pauze, kratke $(s p)$ ili duge $(l p)$ neispunjene pauze, backchannels, produženi vokali, neverbalne i nevokalne pojave), + krnje reči, _prekidanje unutar reči, / pogrešan start, * agramatični oblici, \# \# preklapanje (detaljnije u Ceković-Rakonjac 2012).

${ }^{4}$ Oznake B1 ili B2 ukazuju na nivo testa, a S1-S10 na redne brojeve studenata. 
2. Fokalizacija, funkcija isticanja određenog elementa ili dela teksta, vrši se u J2 putem fokalizatora specialmente, (ne)anche, davvero (2) (pre-test); odnosno proprio, (ne)anche, veramente, davvero (post-test).

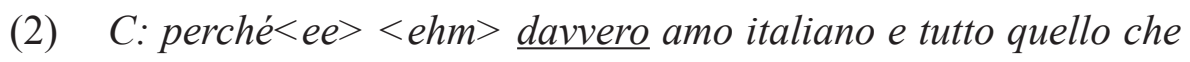
$<$ inspiration $><$ ehm $>$ che che $<$ ehm $>$

E: $<$ mhmh $>$ ? $<$ lp $>$ tutto quello che?

C: che è legato all'Italia $(\mathrm{B} 1, \mathrm{~S} 10)$

\section{Reformulacija:}

3.1. Parafraza: Prvu od tri funkcije reformulacije, parafrazu, obavlja retko ispoljen parafrastički marker dunque (3) (pre-test):

(3) C: però se parliamo di $<e h m>s^{+}<e h m><$ tongue-click $>d i$ $<e e h>d+d+<e h m>d i<e e h>$ viaggia $<a a>$ re dunque $<e e h>$ spo+ spostarsi da una parte all'altra nell'un_a città $E:<m h m h>(\mathrm{B} 1, \mathrm{~S} 2)$

3.2. Korekcija: Neznatno učestaliji, a u službi još jedne reformulacione funkcije, korekcije, kojom student vrši popravku svog iskaza (i to, zajedno sa parafrazom, u sklopu strategija kojima pribegava u cilju svesnog kontrolisanja vlastite produkcije), zabeleženi su oblici poput: $d i-$ ciamo, non i come dire (4) (post-test):

(4) C: ad esempio a Mallorca [foreign word] vivono dal turismo $e<e e>$ se vogliono frequentare un un inver $+<e e h>u<u u>$ / l'univers[z]ità $<e e h>$ che $<e h m>\grave{e}<e e><s p>$ come dire $<$ tongue-click $><e h m>$ ha una certa importanza devono spostarsi e andare alle altre parti del paese o negli altri paesi per studiare $[\ldots](\mathrm{B} 2, \mathrm{~S} 2)$

3.3. Egzemplifikacija: Napokon, u službi egzemplifikacije ili navođenja primera našli su se na pre-testu: non (lo) so (5) i diciamo, a na posttestu od egzemplifikatora zabeleženi su: per esempio, non (lo) so, forse, ad esempio u prethodnom primeru (4).

(5) $C$ : di solito $<$ ehm $>$ indosso $<o o>$ i jeans, una maglietta, le scarpe da ginnastica $<a a><e e h>$ ma anche amo $<0 o>$ vestir + vestirmi elegante $<e e>$ in $\#<E>$ qualche\# occasione speciale E: \#<C><mhmh $>\#$ per esempio? 


$$
\begin{aligned}
& \text { C: }<\text { eeh }>\underline{\text { non lo so }} \text { una festa }<a a>\text {, un compleanno }<o o> \\
& E:<m h m h>(\mathrm{B} 1, \mathrm{~S} 1)
\end{aligned}
$$

\section{Kvantitativna analiza}

Rezultati analize longitudinalnog korpusa ukazuju da se kao najučestalije u italijanskom kao J2 izdvajaju sledeće metatekstualne forme: anche, non (lo) so, poi, eccetera, qualcos'altro (pre-test) i anche, non (lo) so, per esempio, proprio, poi (post-test), odnosno da u pogledu funkcija koje one obavljaju na oba testa dominiraju demarkatori, iza kojih slede egzemplikatori i fokalizatori.

Rezultati su pokazali i da je sa porastom kompetencije došlo do proširenja obima različitih formi i funkcija MDM budući da se, primera radi, korekcija javlja jedino na post-testu. Štaviše, udeo svih DM u ukupnom broju produkovanih reči porastao je između dva testa (za 1,48\%, Tabela 1), baš kao i obim formi markera (za 15, Tabela 2).

\begin{tabular}{|c|c|}
\hline & Studenti III godine \\
\hline Udeo DM (pre-test, B1) & $5,94 \%$ \\
\hline Udeo DM (post-test, B2) & $7,42 \%$ \\
\hline RAZLIKA & $+1,48 \%$ \\
\hline
\end{tabular}

Tabela 1. Porast udela DM u ukupnom broju produkovanih reči

\begin{tabular}{|c|c|}
\hline & Studenti III godine \\
\hline Broj formi DM (pre-test, B1) & 28 \\
\hline Broj formi DM (post-test, B2) & 43 \\
\hline RAZLIKA & +15 \\
\hline
\end{tabular}

Tabela 2. Porast obima formi DM

Osim toga, rezultati su pokazali da je došlo i do uvećanja udela metatekstualnih funkcija u sveukupnom obimu funkcija koje vrše DM zabeleženi u korpusu, i to od $1 / 3$ na pre-testu do $1 / 2$ na post-testu, iako je, ukoliko posmatramo najučestalije funkcije, zapravo opao procenat demarkatora (sa $22 \%$ na $13 \%$ ), za razliku od procenata egzemplifikatora (sa $6 \%$ na $10 \%$ ) i fokalizatora (sa $4 \%$ na $6 \%$ ) koji su ispoljili tendenciju rasta (Tabela 3). 


\begin{tabular}{|c|c|c|c|}
\hline & demarkatori & egzemplifikatori & fokalizatori \\
\hline pre-test, B1 & $22 \%$ & $6 \%$ & $4 \%$ \\
\hline post-test, B2 & $13 \%$ & $10 \%$ & $6 \%$ \\
\hline RAZLIKA & $\downarrow 9 \%$ & $\uparrow 4 \%$ & $\uparrow 2 \%$ \\
\hline
\end{tabular}

Tabela 3. Udeo najučestalijih metatekstualnih funkcija

\section{Zaključak}

Analiza rezultata proisteklih iz longitudinalnog korpusa navela nas je na nekoliko zaključaka u vezi sa onime što se odigrava na srednjem nivou kompetencije u italijanskom kao J2, odnosno između B1 i B2 nivoa, a to je:

- dolazi do proširenja obima formi, među kojima se kao najčešće izdvajaju: anche, non (lo) so, poi, per esempio, eccetera, qualcos'altro, proprio;

- širi se i obim funkcija, budući da se ispoljava i korekcija; lizacija;

- preovladava demarkacija, iza koje slede egzemplifikacija i foka-

- dolazi do porasta udela metatekstualnih funkcija u sveukupnim funkcijama koje markeri vrše (sa $1 / 3$ na pre-testu na $1 / 2$ na post-testu), pri čemu su demarkatori u opadanju, dok su egzemplifikatori i fokalizatori u porastu.

Sem toga, a u vezi sa iznetim hipotezama, analizom sadržanom u ovom radu postignuto je sledeće:

- potvrđene su hipoteze o porastu obima različitih formi MDM sa porastom kompetencije;

- pobili smo, u saglasnosti sa Carlsen (2010), dosadašnje zaključke o prisustvu raznovrsnosti formi DM tek od B2 $2^{+}$nivoa: naime, već od B1/ B2 nivoa širi se repertoar različitih metatekstualnih formi;

- potvrđene su hipoteze o porastu obima funkcija DM od A do C nivoa, a naročito od B1, i kada je reč o MDM;

- u vezi sa hipotezom o prisustvu svih funkcija DM na B nivou, opovrgli smo svoja polazna očekivanja: opravdano je, zapravo, smatrati takvu hipotezu validnom i u pogledu metatekstualnih funkcija, ukoliko se ima u vidu da se izostanak fokalizacije iz transverzalnog korpusa nadomešćuje njenim prisustvom na datom nivou u onom longitudinalnom. 
Imajući u vidu pomenuto širenje obima formi i funkcija markera, zaključujemo da s porastom kompetencije učenik uspeva da umešnije njima vlada $i$ da ih efikasnije koristi. U pogledu najučestalijih metatekstualnih funkcija, primetno je da na višem nivou znanja opada dominacija demarkatora u korist ostalih funkcija, kao što su egzemplifikacija ili fokalizacija. Bilo kako bilo, zaključujemo, međutim, da je neophodno nadalje verifikovati repertoar, kao i sekvencijalnost formi i funkcija DM u međujeziku, i to ne samo onih metatekstualnih. Imajući u vidu sve intenzivnija proučavanja markera u oblasti primenjene lingvistike poslednjih decenija, a naročito nedovoljan broj kvantitativnih i u pravom smislu longitudinalnih studija, prvenstveno onih koje se odnose na italijanski kao J2, pored sticanja boljeg uvida u metatekstualne kompetencije učenika mišljenja smo da ovaj i slični radovi moraju imati za cilj i preciziranje opštih smernica za jedan sistematičniji pristup DM u nastavnoj teoriji i praksi.

\section{Literatura}

Andorno, C. (2007). Apprendere il lessico: elaborazione di segnali discorsivi (sì, no, così). In: Atti del $6^{\circ}$ Congresso Internazionale dell'Associazione Italiana di Linguistica Applicata. Imparare una lingua: recenti sviluppi teorici e proposte applicative, Napoli 9-10 febbraio 2006 (M. Chini et al., eds.), Perugia: Guerra, 95-121.

Andorno, C. (2008). Connettivi in italiano L2 fra struttura dell'enunciato e struttura dell'interazione. In: Competenze lessicali e discorsive nell'acquisizione di lingue seconde (G. Bernini, L. Spreafico \& A. Valentini, eds.), Perugia: Guerra, 481-510.

Bardel, C. (2003). I segnali discorsivi nell'acquisizione dell'italiano L2. In: API: Archivio del Parlato Italiano (C. Crocco, R. Savy \& F. Cutugno, eds.), Napoli: Multimedia press, [DVD].

Bazzanella, C. (1994). Le facce del parlare. Un approccio pragmatico all' italiano parlato. Firenze: La Nuova Italia.

Bazzanella, C. (1995). I segnali discorsivi. In: Grande grammatica italiana di consultazione, vol. 3 (L. Renzi, G. Salvi \& A. Cardinaletti, eds.), Bologna: Il Mulino, 225-257.

Bazzanella, C. \& Borreguero Zuloaga, M. (2011). 'Allora' e 'entonces': problemi teorici e dati empirici. Oslo Studies in Language 3 (1): 7-45.

Bini, M., \& Pernas, A. (2007). Marcadores discursivos en los primeros estadios de adquisición del italiano L2. In: 25 años de Lingüística Aplicada en 
España: hitos y retos. Actas del VI Congreso de la Asociación Española de Lingüistica Aplicada (R. Monroy \& A. Sánches, eds.), Murcia: Editum, 25-32.

Borreguero Zuloaga, M. (2009a). L'espressione dell'avversatività nell'interazione dialogica degli apprendenti di italiano L2: una prospettiva acquisizionale. In: Sintassi storica e sincronica dell'italiano. Subordinazione, coordinazione, giustapposizione. Atti del X Congresso SILFI, vol. 3, Basilea 30 giugno-3 luglio 2008 (A. Ferrari, ed.), Firenze: Franco Cesati, 1489-1504.

Borreguero, M. \& Pernas, P. (2010). Cortesia e scortesia in un contesto di apprendimento linguistico: la gestione dei turni. In: La comunicazione parlata 3. Atti del terzo congresso internazionale del Gruppo di Studio sulla Comunicazione Parlata, SLI, vol. 1, Napoli 23-25 febbraio 2009 (M. Pettorino, A. Giannini \& F. M. Dovetto, eds.), Napoli: Università degli Studi di Napoli L'Orientale, 227-247.

Carlsen, C. (2010). Discourse connectives across CEFR-levels: A corpus based study. In: Communicative proficiency and linguistic development: intersections between SLA and language testing research (I. Bartning, M. Martin \& I. Vedder, eds.), European Second Language Association, 191209. Dostupno na: http://www.eurosla.org/eurosla-monograph-series/ [12.03.2013].

Ceković, N. (2014). I segnali discorsivi nell'interlingua degli studenti universitari di italiano L2. Italica Belgradensia 2: 93-110.

Ceković, N. (2016). Diskursni markeri u govornoj produkciji na italijanskom kao drugom jeziku (Doktorska disertacija). Beograd: Filološki fakultet.

Ceković, N. (2018a). Relations between the Forms and Functions of Discourse Markers and Levels of Competence in L2 Italian: State of the Art. In: Jezici i kulture u vremenu i prostoru VII (S. Gudurić \& B. Radić-Bojanić, eds.), Novi Sad: Filozofski fakultet/Pedagoško društvo Vojvodine, 523531.

Ceković, N. (2018b). Didaktički materijali za italijanski kao L2: (ne)eksplicitni fokus na diskursnim markerima. Anali Filološkog fakulteta 30 (1): 117138.

Ceković-Rakonjac, N. (2012). Ortografska transkripcija govornog korpusa ESNAKIT. In: Digitalizacija kulturne i naučne baštine, univerzitetski repozitorijumi i učenje na daljinu, vol. 3 (A. Vraneš, LJ. Marković \& G. Alexander, eds.), Beograd: Filološki fakultet, 163-182.

Ceković-Rakonjac, N. (2013). ITALBEG corpus parlato di italiano L2. Italica Belgradensia 1: 336-348. 
Ceković, N. \& Janićijević, N. (2017). Scusa, sai, ti dico... Gli equivalenti serbi dei segnali discorsivi italiani di origine verbale. Anali Filološkog fakulteta 29 (2): 51-65.

Ceković, N. \& Radojević, D. (2015). Didattica con i corpora orali di italiano L2. In: The Future of Italian Teaching: Media, New Technologies and MultiDisciplinary Perspectives (C. Ramsey-Portolano, ed.), Newcastle upon Tyne: Cambridge Scholars Publishing, 96-106.

Ceković, N. \& Radojević, D. (2016). La "politraducibilità" dei segnali discorsivi italiani. In R. Scotti Jurić, N. Poropat Jeletić \& I. Matticchio (eds.), Studi filologici e interculturali tra traduzione e plurilinguismo (pp. 451-464). Ariccia: Aracne Editrice

Council of Europe (2001). Common European Framework of Reference for Languages: Learning, teaching, assessment. Cambridge: Cambridge University Press.

Diadori, P., Palermo, M. \& Troncarelli, D. (2009). Manuale di didattica dell'italiano L2. Perugia: Guerra.

Ferraris, S. (2004). Come usano ma gli apprendenti di italiano L1 e L2? In: Atti del $3^{\circ}$ congresso di studi dell'Associazione Italiana di Linguistica Applicata, Perugia 21-22 febbraio 2002 (G. Bernini, G. Ferrari \& M. Pavesi, eds.), Perugia: Guerra, 73-89.

Fung, L. \& Carter, R. (2007). Discourse Markers and Spoken English: Native and Learner Use in Pedagogic Settings. Applied Linguistics 28 (3): 410439.

Guil, P. (2009a). Segnali discorsivi come meccanismi di intensità in italiano L2. In: Fenomeni di intensità nell'italiano parlato (B. Gili Fivela \& C. Bazzanella, eds.), Firenze: Franco Cesati, 223-241.

Guil, P. (2009b). Interazione orale di apprendenti ispanofoni di italiano L2: usi e funzioni di e incipitaria. In: Sintassi storica e sincronica dell'italiano. Subordinazione, coordinazione, giustapposizione. Atti del X Congresso SILFI, vol. 3, Basilea 30 giugno-3 luglio 2008 (A. Ferrari, ed.), Firenze: Franco Cesati, 1505-1519.

Guil, P., Bazzanella, C., Bini, M., Pernas, P., Gil, T., Borreguero, M., Pernas, A., Kondo, C. M. \& Gillani, E. (2008). Marcadores discursivos y cortesía lingüística en la interacción de aprendices de italiano L2. In: Cortesía y conversación: de lo escrito a lo oral. Actas del III Congreso Internacional del Programa EDICE (A. Briz et al., eds.), València: Universitat de València, 711-729.

Hernández, T. (2008). The Effect of Explicit Instruction and Input Flood on Students' Use of Spanish Discourse Markers on a Simulated Oral Proficiency Interview. Hispania 91 (3): 665-675. 
House, J. (2013). Developing pragmatic competence in English as a lingua franca: Using discourse markers to express (inter)subjectivity and connectivity. Journal of Pragmatics 59: 57-67.

Jafrancesco, E. (2015). L'acquisizione dei segnali discorsivi in italiano L2. Italiano LinguaDue 1: 1-39.

Jones, C. (2011). Spoken discourse markers and English language teaching: practices and pedagogies (Doktorska disertacija). University of Nottingham, Nottingham.

Müller, S. (2005). Discourse Markers in Native and Non-native English Discourse. Amsterdam/Philadelphia: John Benjamins.

Nigoević, M. \& Sučić, P. (2011). Competenza pragmatica in italiano L2: l'uso dei segnali discorsivi da parte degli apprendenti croati. Italiano LinguaDue 2: 94-114.

Pernas, P., Gillani, E. \& Cacchione, A. (2011). Costruire testi, strutturare conversazioni: la didattica dei segnali discorsivi come elementi pivot nell'interazione verbale. Italiano LinguaDue 1: 65-138.

Rastelli, S. (2003). Boh. Le interiezioni nella linguistica e nella didattica dell'italiano L2. Itals: Didattica e linguistica dell'italiano come lingua straniera I (3): 35-64.

Romero Trillo, J. (2002). The pragmatic fossilization of discourse markers in non-native speakers of English. Journal of Pragmatics 34: 769-784.

Savy, R. (2005). Specifiche per la trascrizione ortografica annotata dei testi. In: Italiano Parlato, Analisi di un dialogo (F. Albano Leoni \& R. Giordano, eds.), Napoli: Liguori, 1-28.

Wiberg, E. (2003). Interactional context in L2 dialogues. Journal of Pragmatics 35: 389-407.

Wiberg, E. (2004). Strategie interazionali dell'apprendente nel dialogo tra native e non-nativo. In: Il parlato italiano. Atti del Convegno Nazionale, Napoli 13-15 febbraio 2003 (F. Albano Leoni et al., eds.), Napoli: D’Auria Editore, [CD-Rom]. 


\section{Nevena P. Ceković \\ COMPETENZA METATESTUALE DEGLI APPRENDENTI INTERMEDI DI ITALIANO L2}

Riassunto: La nostra ricerca è incentrata sui segnali discorsivi metatestuali, che si profilano come un fattore rilevante di competenza discorsiva e di fluenza pragmatica in una seconda lingua, partendo da un corpus longitudinale, consistente di registrazioni audio e di trascrizioni ortografiche di 100 minuti di interazioni asimmetriche a cui, a distanza di un anno, hanno preso parte 10 studenti serbofoni a livello intermedio di competenza in italiano L2. L'analisi qualitativa e quantitativa ha rivelato le forme e le funzioni più frequenti dei demarcativi, focalizzatori e riformulatori (indicatori di parafrasi, correzione, esemplificazione), illustrati tramite gli esempi d'uso estratti dal corpus. I risultati dell'analisi indicano un ampliamento del volume delle forme e delle funzioni dei segnali metatestuali con il crescere di competenza, nonché un aumento della quota delle funzioni metatestuali nel totale delle funzioni svolte dai segnali discorsivi registrati nel corpus.

Parole chiave: italiano L2, segnali discorsivi metatestuali, competenza pragmatica, studenti serbofoni, corpus. 